\title{
Gênero e maternidade: questões complexas entre natureza e cultura
}

\author{
Gender and maternity: \\ complex issues between nature and culture
}

Larissa Fernandes

Clélia Peretti

Mário Antônio Sanches

\section{Resumo}

A proposta deste trabalho é apresentar questões relacionadas ao tema maternidade a partir de uma crítica de gênero. Gênero neste sentido entendido como perspectiva consciente de semelhança e diferença entre feminino e masculino e deles entre si. Baseando-se em autores e autoras que convergem e divergem em torno desta temática, a intenção não é privilegiar pontos de vista já estabelecidos, mas refletir a questão trazendo à discussão a complexidade da abordagem apresentada. Não há ponto final na reflexão, pois o texto não tem caráter resolutivo para o problema proposto e sim propõe abrir e instigar para a necessidade de uma reflexão inter e transdisciplinar, intelectualmente honesta, que consista numa análise que tenha abrangência teológica, antropológica e bioética sob o crivo de uma perspectiva de gênero.

Palavras-chave: Gênero; Maternidade; Mulher; Parentalidade.

\section{Abstract}

The purpose of this paper is to present issues related to motherhood theme from a gender critique. Gender in this sense as intentional perspective of similarity and difference between male and female and of them together. 
Based on authors and authors that converge and diverge around this theme, the intention is not to privilege views already established, but reflect the issue bringing to the discussion the complexity of the approach. There is no end to reflection, because the text has not resolved character for the proposed problem but proposes to open and instigate the need for inter- and transdisciplinary reflection, intellectually honest, comprising an analysis taking theological scope, anthropological and bioethics in the sieve of a gender perspective.

Keywords: Genre; Motherhood; Women; Parenting.

\section{Introdução}

O cenário contemporâneo, influenciado pela luta dos movimentos feministas, aponta a mulher ocupando e transitando entre os espaços público e privado, nos quais vem exercendo dentro deles papéis considerados até então de caráter masculino. Funções que por muito tempo foram detidas pelo monopólio patriarcal recebem uma nova impressão no modo de atuação próprio do gênero feminino. Equivocadamente o feminismo é muitas vezes entendido como dualismo de gêneros. Contudo, as questões de gênero não se restringem ao público feminino, mas trazem para o diálogo temas sobre desigualdade, vulnerabilidade, sexualidade, corpo e reprodução, e é uma variável de pesquisa para a compreensão e análise dos conflitos morais em educação, trabalho, saúde e família. Deste modo, torna-se importante uma análise de como cada grupo social transforma a natureza em cultura, e como antropologicamente se transformam machos e fêmeas em homens e mulheres, e assim vão se constituindo os valores do feminino e do masculino em cada sociedade.

\section{Gênero e maternidade: um olhar histórico}

Em nossa sociedade, como na maioria das sociedades, as mulheres não apenas geram filhos, mas elas também maternam, assumindo a responsabilidade inicial pelo cuidado da criança, dedicando mais tempo a elas e mantendo os primeiros laços emocionais com os bebês. Segundo Nancy Chodorow, até mesmo quando as mães biológicas não proporcionam os cuidados iniciais, outras mulheres acabam assumindo esta responsabilidade ${ }^{1}$. Do ponto de vista

${ }^{1}$ CHODOROW, Nancy. Psicanálise da Maternidade. Uma crítica a Freud a partir da mulher. Rio de Janeiro: Rosa dos Tempos, 1978, p. 17. 
histórico houve mudanças de caráter físico e biológico no processo de gravidez e cuidado infantil. Contudo, permanece o fato de que a maternidade ocorra num contexto de parentalidade, uma vez que o papel da atividade materna adquire cada vez mais uma significação psicológica e ideológica também, definindo, deste modo, a vida das mulheres. Chodorow ${ }^{2}$ faz uma análise histórica do contexto familiar nos últimos dois séculos que influenciaram no exercício da parentalidade de homens e mulheres. Há dois séculos, o casamento, especialmente para as mulheres eram essencialmente sinônimo de criação de filhos e os cuidados maternos e paternos duravam desde o início do casamento até a morte dos parceiros matrimoniais. E normalmente as mulheres morriam durante um dos muitos partos. Para Hewlett,

Nos tempos pré-modernos, a média de mulheres enfrentava 8 gravidezes, 6 nascimentos vivos com $10 \%$ de chance de morrer no parto (cerca de um quarto das mortes femininas entre 15 e 50 anos eram devidas a causas obstétricas). Entre as que sobreviviam ao parto, muitas ficavam tão dilaceradas durante o trabalho de parto e o parto propriamente dito que acabavam aleijadas para o resto da vida. E o golpe de misericórdia: uma larga proporção desses bebês duramente obtidos morreria. Até o começo do século XIX, uma mulher podia esperar que, ao menos duas de suas crianças morreriam antes dos 5 anos $^{3}$.

Mas antes da revolução industrial, a maternação não dominava a vida das mulheres por completo, estas arcavam também com uma série de outros trabalhos produtivos. Antigamente, o lar era o núcleo produtor da sociedade e não apenas reprodutor - onde marido e mulher, juntamente com seus filhos e filhas formavam uma espécie de cooperativa. Com isso, na maioria das sociedades as mulheres desempenhavam responsabilidades produtivas como alimentação, vestuário, agricultura, limpeza e organização da casa, e responsabilidades reprodutivas como a geração e criação dos filhos.

Entretanto, nos últimos dois séculos, a industrialização reconfigurou os modelos de família afastando a presença dos avós e dos filhos adultos nos lares. Houve uma queda nas taxas de fertilidade e mortalidade infantil, as pessoas vivem mais tempo, e aumentou o tempo das crianças na escola. Com

\footnotetext{
${ }^{2}$ Ibidem, pp. 18-19.

${ }^{3}$ HEWLETT, Sylvia Ann. Maternidade tardia: mulheres profissionais em busca da realização plena. São Paulo: Novo Século, 2008, p. 227.
} 
a ascensão do capitalismo, expandiu-se enormemente a produção fora de casa, diminuindo assim a produção dentro do próprio lar, uma vez que muitos dos serviços realizados tornaram-se mercadorias, produzidas em massa nas fábricas. Assim, lar e local de trabalho passam a ser distintos, e a casa já não é vista como um local de trabalho.

Essas transformações produziram mudanças efetivas nas famílias e na vida das mulheres. A família passa a ser mais nuclear, restringindo seu papel à esfera pessoal da sociedade, perdendo assim sua influência educacional e religiosa. As mulheres assumiram um papel na família centrado no cuidado dos filhos e dos homens, exercendo a função maternal de forma mais, para além de fazer-lhes a comida e deixar a casa limpa. Enfim, as funções produtiva e reprodutiva das mulheres mudaram, e até mesmo a família mudou:

Um século atrás as mulheres eram juridicamente inexistentes, presumidas sob a posição política e legal do marido. Hoje as mulheres podem votar, e há o reconhecimento generalizado de que devam ter direitos iguais perante a lei. Há um século, poucas mulheres podiam ganhar a vida de modo independente (...). As mulheres hoje têm dois ou três filhos, e às vezes preferem ter nenhum. A taxa de divórcio é muito mais elevada, e as pessoas casam-se mais tarde 4 .

Embora estes e outros avanços sejam reconhecidos, as mulheres continuam a maternar, e a maioria das pessoas ainda se casa. Mulheres ainda sofrem discriminação no trabalho, na família com responsabilidades desiguais de gênero, e a violência contra as mulheres ainda é um escândalo. Embora os dados apontem que as mulheres vivem mais do que os homens por causa de vantagens biológicas e comportamentais, em alguns locais estas vantagens são anuladas pela discriminação baseada no gênero, que torna a expectativa de vida ao nascer do sexo feminino menor ou igual à do sexo masculino. Outro fator se dá por condições que são vivenciadas tão somente pelas mulheres, cujo impacto negativo é sofrido apenas por elas, como a gravidez e o parto, que mesmo não sendo doenças, acarretam, por processos biológicos e sociais, riscos à saúde e requerem cuidados. Com isso, percebe-se também que as iniquidades de gênero estão ligadas também à saúde da mulher ${ }^{5}$.

${ }^{4}$ CHODOROW, Nancy. Psicanálise da Maternidade. Uma crítica a Freud a partir da mulher. Rio de Janeiro: Rosa dos Tempos, 1978, p. 21.

${ }^{5}$ OMS - ORGANIZAÇÃO MUNDIAL DA SAÚDE. Mulheres e Saúde: evidências de hoje, agenda de amanhã. Trad. Português. Brasil: Ministério da Saúde, 2011, p. XI. 
No antigo Israel, a perpetuidade e a força da tribo dependiam da descendência, da prole dada pelas esposas. Esta importância dada pelo clã a essa perpetuidade da descendência se manifestava através de costumes que, por vezes, oprimiam a situação da mulher. A mulher estéril era obrigada a consentir que seu marido mantivesse relações sexuais com uma serva para gerar filhos, pois a esposa era apreciada mais pelo seu papel reprodutor do que pelo seu valor pessoal. Se a mulher enviuvasse sem dar filhos tinha que se casar com um irmão do marido, e desse modo, o primogênito seria o herdeiro do falecido. Neste contexto, não se apreciava uma mulher que não fosse também mãe. Athalya Brenner, em sua obra $A$ Mulher Israelita ${ }^{6}$ (2001, p.195) aponta que o valor supremo da sociedade bíblica estaria no princípio de preservação e de perpetuidade do povo.

A mulher cidadã de Atenas ou de Roma tinha durante toda a sua vida, uma condição jurídica de menor, pouco diferente da condição de seus filhos? $\mathrm{Na}$ era cristã, a palavra de Jesus Cristo começou a surtir efeito para que as coisas se modificassem, pelo menos em teoria. Aparecem diversas mulheres no itinerário da sua missão, marcados por encontros singulares com cada uma delas, confirmando, deste modo, a "novidade de vida" evangélica. João Paulo II, em sua Carta Apostólica Mulieris Dignitatem ${ }^{8}$ fala que essa atitude é uma novidade instigante não somente para os inimigos de Jesus, mas até mesmo para seus discípulos.

Ao pregar o amor ao próximo, o Cristo punha um freio à autoridade, de onde quer que viesse. Reforçava o companheirismo e, portanto, a igualdade dos esposos, fazendo do casamento uma instituição divina. Assim, punha fim a um poder exorbitante do marido, o poder de repúdio, e à poligamia. A mensagem de Cristo era clara: marido e mulher eram iguais e partilhavam dos mesmos direitos e deveres em relação aos filhos. Se alguns apóstolos e teólogos obscureceram a mensagem com sua interpretação, chegando, como veremos, a traí-la, a palavra de Cristo modificou, em boa parte, a condição da mulher?.

${ }^{6}$ BRENNER, Athalya. A Mulher Israelita: papel social e modelo literário na narrativa bíblica. São Paulo: Paulinas, 2001, p. 195.

${ }^{7}$ Cícero (Pro Domo, 30) lembra que o pai tinha sobre o filho: direito de vida e de morte, direito de castigá-lo à sua vontade, de mandá-lo flagelar, de condená-lo à prisão, de excluí-lo, enfim, da família.

${ }^{8}$ JOÃO PAULO II. Carta Apostólica Mulieris Dignitatem, $\mathrm{n}^{\mathrm{o}}$ 12, p. 49.

${ }^{9}$ BADINTER, Elisabeth. B126a Um Amor conquistado: o mito do amor materno. Tradução de Waltensir Dutra. Rio de Janeiro: Nova Fronteira, 1985, pp. 28-29. 
Contudo, o pensamento que prevaleceu e sustentava a filosofia política no século XVII era baseado em Aristóteles, o primeiro a justificar a autoridade do homem como legítima porque repousa sobre a desigualdade natural que existe entre os seres humanos. Seguindo esta linha de pensamento a mulher era desvalorizada do ponto de vista metafísico, uma vez que encarna o princípio negativo, a matéria, contrariamente ao homem, que personifica a forma, princípio divino sinônimo de pensamento e de inteligência. Como cidadã, esta é essencialmente inferior ao homem, seja qual for a sua idade. Dotada de uma frágil capacidade de deliberação, o filósofo deduz que sua opinião não é digna de consideração e sua honra residia num "modesto silêncio". É "natural" que a mais acabada das criaturas comande os demais membros da família, e isso de duas maneiras: em virtude de sua semelhança com a divina, como "deus comanda suas criaturas", e em virtude de suas responsabilidades políticas, econômicas e jurídicas, como um "Rei comanda seus súditos". Esses dois temas aristotélicos serão profusamente retomados pela teologia cristã e pelos teóricos da monarquia absoluta ${ }^{10}$.

\subsection{Instinto materno: natureza ou cultura?}

Há autores, como a filósofa francesa Elisabeth Badinter, que defendem o amor materno como um mito, consequência de uma mera construção cultural. Para ela o amor materno não constitui um sentimento inerente à condição de mulher, não é um determinismo, mas algo que se adquire. Baseada num exame de dados históricos dos séculos XVII e XVIII, Badinter afirma que o conceito de amor materno é produto da evolução social desde princípios do século XIX. Anteriormente o amor da mãe aos filhos era outro: as crianças eram normalmente entregues, desde tenra idade, às amas, para que as criassem, e só voltavam ao lar depois dos cinco anos. Dessa maneira, como todos os sentimentos humanos, ele varia de acordo com as flutuações socioeconômicas da história.

Estar separado do ser amado pode estimular nossos sentimentos, mas ainda assim é necessário que estes tenham existido previamente, e que esta ausência não se prolongue extensivamente. $\mathrm{O}$ amor não se exprime em todo momento, e pode perdurar em estado latente. Porém, se não há um cuidado, um cultivo, ele pode se debilitar ao ponto de desaparecer. Deste modo, Badinter diz que:

${ }^{10}$ Ibidem, p. 32. 
Quando as mães se separavam de seus filhos por três ou quatro anos, que sentimento materno podiam experimentar quando voltavam para casa? Penso, enfim, como os psicanalistas, que não há amor sem algum desejo, e que a ausência da faculdade de tocar, mimar ou beijar é pouco propícia ao desenvolvimento do sentimento. Se a criança não está ao alcance de sua mão, como poderá a mãe amá-la? Como poderá apegar-se a ela?"1

Os que defendem o amor materno como imutável são evidentemente os que postulam a existência de uma natureza humana que só se modifica na "superfície". E neste caso a cultura não passa de um epifenômeno. Para estes, a maternidade e o amor que a acompanha estariam inscritos desde toda a eternidade na natureza feminina. Desse ponto de vista, uma mulher é feita para ser mãe, e mais, uma boa mãe. Toda exceção à norma será considerada em termos de exceções patológicas, como a mãe indiferente. Em princípio, a lei natural não admite nenhuma exceção ${ }^{12}$. Contudo, é necessário admitir que a contingência e o particular são o apanágio do ser humano, um dado antropológico. Mas o fardo da contingência dos comportamentos e dos sentimentos é também a única falha pela qual se exprime sua liberdade.

Hoje, uma mulher pode desejar não ser mãe: trata-se de uma mulher normal que exerce a sua liberdade, ou de uma enferma no que concerne às normas da natureza? Não teremos, com excessiva frequência, tendência a confundir determinismo social e imperativo biológico? Os valores de uma sociedade são por vezes tão imperiosos que têm um peso incalculável sobre os nossos desejos. Por que não poderíamos admitir que quando não é valorizado por uma sociedade, e, portanto, não valoriza a mãe, o amor materno não é mais necessariamente desejo feminino? ${ }^{13}$.

É em virtude dessa "natureza boa" que se formula o seguinte silogismo: dado que a espécie sobrevive e que o amor materno é necessário a essa sobrevivência, o amor materno existe necessariamente, mas não em todas as mulheres. Segundo Badinter e Chodorow, não é só o amor que leva a mulher a cumprir seus "deveres maternais". A moral, os valores sociais, ou religiosos, podem ser incitadores tão poderosos quanto o desejo da mãe. É certo que a antiga divisão sexual do trabalho pesou muito na atribuição das funções

\footnotetext{
${ }^{11}$ Ibidem, p. 14.

${ }^{12}$ Ibidem, p. 14.

${ }^{13}$ Ibidem, p. 15.
} 
da "maternagem" à mulher, e que, até ontem, esta se afigurava o mais puro produto da natureza. Será preciso lembrar também que em outras sociedades — e não das menores - a "boa natureza maternal" tolerava que se matassem as crianças do sexo feminino ao nascer? ${ }^{14}$.

\section{Planejamento da Parentalidade}

O uso da expressão 'planejamento da parentalidade', tem por objetivo distanciar-se da ideia reduzida ao controle de natalidade e não quer insistir diretamente na instituição família, nem nos métodos de concepção e contracepção, mas quer enfatizar a condição de ser pai e ser mãe. Independente das definições de famílias, pensar a parentalidade é pensar a acolhida, o afeto e o cuidado dos filhos, ou seja, a ênfase não se coloca no método utilizado, mas no desejo de ter filhos e no bem estar deles. Com isto a família se justifica na medida em que se torna espaço de acolhida, afeto e cuidado para com os seus membros, e com os filhos em particular.

É possível distinguir os projetos ou planejamento da parentalidade por cinco grupos a seguir, sendo o primeiro deles o planejamento da parentalidade explícito, quando os casais planejam e decidem ter ou não filhos em um momento estabelecido, programado. $\mathrm{O}$ segundo grupo diz respeito ao planejamento da parentalidade implícito, ou seja, quando os filhos fazem parte do projeto de vida do casal, embora chegue num momento não planejado explicitamente, mas que são acolhidos nesse contexto, ainda que ocorra alguns conflitos. Há ainda um terceiro grupo cujos filhos são gerados de modo indesejado, mas que posteriormente os próprios pais ou outras pessoas os acolhe assumindo a parentalidade. Neste caso, chama-se de planejamento de parentalidade post factum. Os exemplos disso são mães ou pais solteiros que não haviam optado pela maternidade/paternidade naquele momento, mas assumem seus filhos com responsabilidade e passam a integrá-los em seus projetos de vida Por fim, há aquelas situações em que a parentalidade não é desejada, e esse quarto grupo gera filhos em contextos de completa negação da parentalidade, levando às consequências do aborto ou de uma rejeição sistemática da criança ${ }^{15}$.

${ }^{14}$ BADINTER, Elisabeth. B126a Um Amor conquistado: o mito do amor materno. Tradução de Waltensir Dutra. Rio de Janeiro: Nova Fronteira, 1985, p. 17.

${ }^{15}$ SANCHES, Mário Antonio. Reprodução assistida e bioética: Metaparentalidade. São Paulo: Ave Maria, 2013, pp. 42-43. 
Além da necessidade de direitos trabalhistas às mulheres mães, um dos maiores conflitos surge quando nos deparamos com a situação de pessoas com filhos ou mulheres grávidas sem terem um projeto de parentalidade. Em nossa sociedade atual, os dados indicam alto índice de partos abortados deliberadamente, mas certamente o aborto não é a única consequência da falta de planejamento familiar e a gravidez é o centro de situações com fortes implicações para a mãe, para as crianças, para as famílias e para os serviços de saúde. Considera-se que alguns eventos adversos relacionados com a reprodução registrados em saúde - podem ter forte relação com a falta de projeto de parentalidade: gravidez na adolescência, partos de mães solteiras, aborto, abandono de recém-nascidos, encaminhamento para adoção, mortalidade materna e mortalidade infantil.

As causas responsáveis pelo aumento da fragilidade das mulheres durante a gravidez, que as expõe ao maior risco de morte, são: desinformação, baixa escolaridade, desnutrição, baixa renda, discriminação étnica, ausência de amparo familiar ou do parceiro e grau de exposição à violência doméstica. Contudo, se unem a esses fatores o fato de uma gestação indesejada e, consequentemente, à prática do aborto, que tornam evidente a relação entre a desigualdade socioeconômica, a dificuldade no acesso aos serviços de saúde e o maior estado de vulnerabilidade das mulheres ante uma gravidez não desejada.

A relação entre contracepção e mortalidade materna parece óbvia, pois diminuindo a taxa de gravidez diminui a taxa de mortalidade materna. Mas esta atitude não resolveria efetivamente, pois poderíamos imaginar mortalidade materna zero obtendo gravidez zero. Entendemos que o importante é diminuir duas ocorrências: primeiro a percentagem de mortalidade materna por parto; segundo o número de gravidezes não desejadas no momento da concepção. Pois quando a gravidez é desejada, planejada, há uma tendência a ocorrer num contexto de maiores condições de cuidados pré-natais, de parto e pós-parto.

\subsection{Reprodução e sexualidade: o valor ético do corpo}

O corpo é um tema complexo, pressupõe a superação dos reducionismos de toda espécie, principalmente do dualismo corpo e alma tão presentes na visão ocidental. Embora teoricamente tenha-se avançado com o resgate bíblico e patrístico na reflexão sobre a corporeidade, há ainda um longo caminho de integração teórico-prática. É possível falar, na teologia, de planejamento da reprodução, sem apoiar as teses de controle e submissão do corpo? Para o 
sociólogo Le Breton, essa apologia ao corpo parece profundamente dualista, como se o corpo pudesse ser analisado fora do ser humano concreto. Há um discurso abundante convidando à "libertação do corpo", de modo me que ele é colocado como algo distinto do ser humano, como uma posse, um alter ego, e o ser humano como um sujeito suposto ${ }^{16}$.

Neste sentido, o corpo pode ser visto como o lugar a partir do qual alguém oprime ou liberta outrem. De fato, tanto a opressão como a libertação passam pelo corpo. Por esse motivo, essa intrínseca relação permite questionar a compreensão corriqueira de que poder seja algo abstrato, invisível, intocável, alienado do corpo. O poder é uma realidade concreta, visível, palpável, corporal; que se materializa no corpo. Com isso, há um conjunto de pedagogias que constroem a educação do corpo, até mesmo nossa própria fisiologia vai ganhando contornos bem culturais. A forma como se lida com o corpo não possui apenas um aspecto subjetivo, mas assume um caráter ético-social que exige recuperar o seu valor filosófico e teológico.

Rose Marie Muraro ${ }^{17}$ em crítica à análise freudiana do corpo e da sexualidade feminina, apresenta uma visão mais integrada da sexualidade feminina na relação entre mente e corpo e corpo e alma, para além da genitalidade. Neste sentido:

A mulher, então desenvolve as qualidades dessa alma que estão integradas com o corpo e que o homem reprime: a emoção, a relação com o outro, a comunhão, a partilha. $\mathrm{O}$ dar-se, para ela não é fonte de morte, mas fonte de mais vida, inclusive biologicamente. Ela se dá ao homem e a vida brota dela. O seu ego continua sendo a superfície sensível do corpo. A intuição, a adivinhação do corpo, o cuidado com o outro, para ela não se originam de um masoquismo, mas de uma exuberância, porque sabe que dela pode brotar a vida.

O cristianismo anuncia uma autêntica revolução a respeito do corpo, valorizando a carnalidade como lugar da experiência de Deus. João Paulo II, em sua obra Amor e Responsabilidade, um estudo ético, desenvolve a relação entre sexologia e ética, acentuando que o objeto próprio da ética sexual não são absolutamente só os problemas do corpo e do sexo, mas as questões e

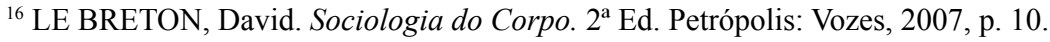

${ }^{17}$ MURARO, Rose Marie; BOFF, Leonardo. Feminino e masculino: uma nova consciência para o encontro das diferenças. Rio de Janeiro: Sextante, p. 164.
} 
os problemas do amor pessoal da mulher e do homem, que são intimamente ligados às questões do corpo e do sexo ${ }^{18}$. Por isso também a ética sexual não pode ser reduzida à sexologia... ${ }^{19}$. Analisando o amor sob o aspecto psicológico, o autor chama a atenção para o valor do corpo e do sexo, que é objeto próprio das reações sensitivas, constatando, ao mesmo tempo, que estas reações fornecem a matéria-prima do amor entre a mulher e o homem. Esta visão supera um conceito estreito do matrimônio como um princípio apenas reprodutivo, resgatando também seu princípio unitivo. Ou seja, coloca as bases da relação conjugal/sexual no amor ${ }^{20}$. Depois entra na questão da procriação, mas abordando a necessidade de uma paternidade/maternidade responsável, em que "numa convivência conjugal, tal convivência deverá ser acompanhada de uma atitude consciente e voluntária contida na afirmação: Posso ser mãe, posso ser pai" ${ }^{21}$.

\section{Conclusão}

No âmbito da Teologia os estudos focam prioritariamente a defesa da vida e da dignidade da criança. Contrariamente, no âmbito da Saúde os estudos focam prioritariamente a defesa da vida e da dignidade da mulher. Uma abordagem teológica na perspectiva da Bioética contribui para uma visão mais ampla que possa considerar a realidade a partir de perspectivas que permitam contemplar os dois focos da questão: a dignidade da mãe e da criança. É questionável a postura condenatória que se pode tomar no trabalho de conscientização do valor da vida, com abordagens excludentes que apontam a incapacidade de defender valores pela força moral que eles próprios possuem.

Há ainda uma tendência apontando que as novas gerações irão conviver com as diferentes configurações familiares, o que poderá favorecer a compreensão sobre a possibilidade de se viver a vida na diversidade. Porém, esse dado não é suficiente. Ao falar de planejamento da parentalidade é necessário

\footnotetext{
${ }^{18}$ JOÃO PAULO II. Amor e Responsabilidade: estudo ético. São Paulo: Loyola, 1982, p. 235.

${ }^{19}$ Ibidem, p. 236.

${ }^{20} \mathrm{O}$ princípio unitivo do amor conjugal é um conceito introduzido Tomas Sanches, teólogo espanhol do século XVI, o primeiro a escrever um tratado completo sobre relacionamento conjugal (Santo Sacramento do Matrimônio) e pelo teólogo leigo Dietrisch Hildebrando em 1925 que declara pela primeira vez que o ato sexual no amor conjugal é um relacionamento legítimo. E em 1935 o teólogo Herbert Doms coloca na perspectiva cristã a sexualidade no relacionamento conjugal como elemento de santificação.

${ }^{21}$ Ibidem, p. 204.
} 
identificar o modelo tradicional de família, junto aos novos arranjos familiares. Fazer parte de um novo formato de família não prova que os modelos tradicionais tenham sido problemáticos ou inapropriados. Nem tudo o que é tradicional é ruim e nem tudo o que é novo, é melhor, necessariamente. E vice-versa. É imprescindível que uma crítica seja feita, dentro mesmo das novas famílias, que, podem perder a capacidade de serem críticas em relação a si mesmas. E aqui, a análise deve ser de uma forma mais específica na condição de ser pai e ser mãe nessas configurações familiares.

Para que cada criança que nasça seja bem-vinda é relevante que cada gravidez seja planejada, pois quando isto não ocorre, instaura-se uma situação de tensão que nem sempre tem resultado favorável ao acolhimento da criança. Por isso o amadurecimento, sem pressa, dos projetos de parentalidade podem favorecer para que este se efetive nas melhores condições possíveis, como parte integrada no projeto de vida das pessoas envolvidas, rumo a um dos maiores desafios contemporâneos: enfrentar a carência de um modelo confiável e funcional de serem pais no mundo em impactante mudança.

Contudo, nem sempre é assim que acontece, a realidade apresenta muitas variáveis e a complexidade do tema abordado exige honestidade intelectual, pois se trata de um conflito moral que incide em vários âmbitos do conhecimento que convergem e divergem entre si, expondo o limite para um fechamento da questão quando se impõe uma demarcação da definição de cultura ou de natureza. Reconhecer o simples fato de que mulheres e homens são diferentes, não apenas quanto à sua natureza, mas também quanto ao seu desempenho social, é o primeiro passo no caminho que somos desafiados a percorrer para garantir os direitos de cidadania das mulheres.

\section{Referências bibliográficas}

BADINTER, Elisabeth. B126a Um Amor conquistado: o mito do amor materno. Elisabeth Badinter; tradução de Waltensir Dutra. Rio de Janeiro: Nova Fronteira, 1985.

BRASIL. Ministério da Saúde. Manual dos comitês de mortalidade materna.

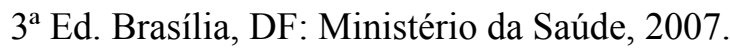

BRENNER, Athalya. A Mulher Israelita: papel social e modelo literário na narrativa bíblica. São Paulo: Paulinas, 2001. 
CHODOROW, Nancy. Psicanálise da Maternidade. Uma crítica a Freud a partir da mulher. Rio de Janeiro: Rosa dos Tempos, 1978. Título original: The Reproduction of Mothering: Psychoanalysis and the Sociology of Gender.

HEWLETT, Sylvia Ann. Maternidade tardia: mulheres profissionais em busca da realização plena. São Paulo: Novo Século, 2008.

FOUCOUALT, Michel. Microfisica do Poder. São Paulo: Paz e Terra S/A, 2006.

JOÃO PAULO II. Amor e Responsabilidade: estudo ético. São Paulo: Loyola, 1982.

JOÃO PAULO II. Carta Apostólica Mulieris Dignitatem. Sobre a Dignidade e a Vocação da Mulher. $6^{\mathrm{a}}$ Ed. São Paulo: Paulinas, 2005.

LE BRETON, David. A sociologia do corpo. Tradução de Sonia M.S. Fuhrmann. $2^{\text {a }}$ Ed. Petrópolis: Vozes, 2007.

MURARO, Rose Marie; BOFF, Leonardo. Feminino e Masculino: uma nova consciência para o encontro das diferenças. Rio de Janeiro: Sextante, 2002.

OMS - ORGANIZAÇÃO MUNDIAL DA SAÚDE. Mulheres e Saúde: evidências de hoje, agenda de amanhã. Trad. Português: Brasil: Ministério da Saúde, 2011.

SANCHES, Mário Antonio. Reprodução assistida e bioética: Metaparentalidade. São Paulo: Ave Maria, 2013.

Larissa Fernandes

Mestranda em Teologia com ênfase em Bioética pela PUCPR Curitiba / PR - Brasil E-mail: larissa.arca@gmail.com

Clélia Peretti

Doutora em Teologia pela Escola Superior de Teologia de São Leopoldo-RS Docente do Programa de Pós-Graduação em Teologia PUCPR Curitiba / PR - Brasil E-mail: cpkperetti@gmail.com 
Mário Antônio Sanches

Doutor em Teologia pela EST/IEPG

Diretor do Programa de Pós-Graduação em Bioética da PUCPR Docente do Programa de Pós-Graduação em Teologia da PUCPR

E-mail:m.saches@pucpr.br

Recebida em: 02/03/15

Aprovada em: 19/05/15 